ISSN $1676-3742$

\title{
A Teoria documentária do Pentateuco Aplicação e limites na análise de Nm 16-17
}

Vicente Artuso

\section{Resumo}

O pesquisa retoma a questão da validade da teoria documentária das fontes e seu desenvolvimento. Aponta sua contribuição aplicada ao texto de $\mathrm{Nm}$ 16-17, mas sobretudo seus limites. Isso se deve ao caráter fragmentário dos textos e a variedade de opiniões e incerteza na separação das fontes. Os elementos literários de unidade são mais determinantes para o entendimento do texto, do que as rupturas. Mais que uma junção de diferentes tradições, o texto pode ser fruto do desenvolvimento de uma história primitiva, que foi meditada e desenvolvida por novos enfoques em contextos diferentes. Seu objetivo foi legitimar o sacerdócio de Aarão no poder. A história serve para intimidar os levitas pretendentes ao sacerdócio mostrando que ninguém que não seja descendente de Aarão pode se aproximar para oferecer incenso.

Palavras-chave: Poder, Sacerdócio, Aarão, Conflito.

\begin{abstract}
The survey takes up the question of the validity of the theory of documentary sources and their development. Aim your contribution applied to the text of Num 16-17, but above its limits. This is due to the fragmentary nature of the texts and the variety of opinions and uncertainty in source separation. The literary elements of unity are more crucial for understanding the text, it breaks. More than a coming together of different traditions, the text can be the
\end{abstract}


result of the development of an early history, which was meditated upon and developed by new approaches in different contexts. His goal was to legitimize the priesthood of Aaron in power. The story serves to intimidate the Levites to the priesthood applicants showing that anyone who is not a descendant of Aaron can approach to offer incense.

Keywords: Power, Priesthood, Aaron, Relationship Conflict.

\section{Introdução}

Retomamos o status quaestionis em relação as fontes do pentateuco em vista de situar os leitores na problemática da análise diacrônica de Nm 16-17¹. O presente estudo apresenta os valores e limites constatados a partir da aplicação da crítica das fontes a um texto compósito. A questão que se levanta é a maneira de afrontar os problemas concretos de um texto difícil. Até que ponto se pode prescindir da crítica literária clássica, na análise concreta de um texto? Pode-se conciliar diacronia com sincronia? São questões enfrentadas na prática da exegese face às rupturas e incongruências nas narrativas. Apresentamos uma análise estilística e narrativa detalhada do texto em questão ${ }^{2}$. Porém as dificuldades levantadas pelos críticos, não podem ser ignoradas e devem ser tratadas de forma mais integrada na abordagem do texto final. Esta análise crítica da composição de Nm 16-17 será objeto de futura publicação.

\section{Retomando o status quaestionis da crítica do Pentateuco}

É conhecida a crise que se estabeleceu a partir de 1970 sobre a teoria documentária em relação à análise dos textos do Pentateuco ${ }^{3}$. Pelo menos na sua

\footnotetext{
${ }^{1}$ Cf. ARTUSO, V. “As revoltas contra Moisés e Aarão em Nm 16-17”. Atualidade Teológica 27 (2007), pp.372-375.

${ }_{2}^{2}$ ARTUSO, V. A revolta de Coré, Datã e Abiram. Análise estilístico-narrativa e interpretação. São Paulo, Paulinas, 2008.

${ }^{3}$ A crise consiste em colocar em questão a teoria documentária clássica que distinguia quatro fontes para o Pentateuco: Javista do tempo de Davi e Salomão, Eloísta do reino do Norte próximo ao tempo de Amós e Oséias, Deuteronomista da reforma de Josias em 622 a.C., e o Sacerdotal, exílico ou pós-exílico (SKA, J. L. Introduzione alla lettura del Pentateuco, Roma: Edizioni Dehoniane, 2000, p. 5-6). Esta situação de crise estende-se há décadas. "Por ocasião do quinto congresso mundial de estudos judaicos já em 1969, R. Rendtorff se mostrava muito crítico com a hipótese dos documentos. A partir daquela data, a aparente "imutabilidade" da
} 
forma rígida, a teoria documentária clássica não pode ser aceita. Por exemplo a datação tradicional das fontes sofreu uma reviravolta e a existência da fonte Javista é negada e poucos ainda a aceitam. A fonte Eloísta há muito tempo é negada e até mesmo a existência da fonte sacerdotal é colocada em questão ${ }^{4}$. A investigação atual é marcada por um distanciamento da teoria documentária e por uma ruptura com a mesma. A tendência atual da investigação é a de retornar aos antigos modelos representados pelas hipóteses fragmentária e complementaria ${ }^{5}$. Estão em alta especialmente os métodos sincrônicos de análise, baseados nas ciências da linguagem. Assim, a tradição antigamente chamada Javista, para aqueles que ainda a aceitam, não pode ser tão antiga como do tempo de Salomão. Poucos estudiosos a defendem e julgam até mesmo que a sigla $\mathrm{J}$ (Javista) deva ser banida ${ }^{6}$. Um autor, outrora bem ligado ao consenso clássico como $\mathrm{H}$. Seebass há muito tempo aceita a posição, já seguida por outros, de que dificilmente podemos reconhecer as "fontes" em Ex-Nm, admitindo, mesmo para o Gênesis muito material pós-exílico que não poderia ser atribuído às fontes clássicas ${ }^{7}$.

Além da diversidade de opiniões sobre a história da composição do Pentateuco, em pouco espaço de tempo, surgiram novas hipóteses com a tendência de situar a origem das tradições escritas do Pentateuco numa época

teoria documentária se tornou movediça e sua fortaleza quebradiça" (cf. GARCIA LOPES, F. O Pentateuco, São Paulo: Ave Maria, 2004, p. 41). Sobre a questão da crise da teoria documentária, cf. DE PURY, A.; RÖMER, T. O Pentateuco em questão: Posição do problema e breve história da pesquisa. In: O Pentateuco em questão, Petrópolis: Vozes, 2002, p. 15-84; HAUDEBERT, P. (Dir.). Le Pentateuque: Débats et recherches. XIV congrés de L’Association Catholique Française pour L’etude de la Bible. Paris, Cerf, 1992, pp.30-55; GARCIA LOPES, F. O Pentateuco, p. 30-55; RÖMER, Th. L'Histoire redactionnelle des premiers livres de la Bible, Estúdios Bíblicos 62 (2004), pp. 137-154.

${ }^{4}$ Por exemplo A. F. CAMPBELL e M. A. O'BRIEN (Rethinking the Pentateuch. Prolegomena to the Theology of Ancient Israel, 2005). J. L. SKA, ao apresentar essa pesquisa destaca que os autores negam a existência do relato sacerdotal em Gn 1-11 e mostram a fragilidade dos critérios de identificação desta fonte: os nomes divinos, o interesse pelas genealogias e o interesse pelas datas. Os autores, no entanto propõem uma nova possibilidade de interpretação do pentateuco, que não exclui outras (cf. SKA, J. L. Res Bibliographicae. Le Pentateuque à l'heure de ses usagers. Bíblica. 87 (2006) fasc. 1, p. 98-99).

${ }^{5}$ Cf. GARCIA LOPES, F. O Pentateuco, p. 41.

6 SKA J. L Introduzione alla lettura del Pentateuco, p. 165; F. GARCIA LOPES (O Pentateuco, p. 278) ao comentar Ex 7-11, sequer cita a sigla Javista (J ou JE) e prefere falar de elementos pré-sacerdotais entrelaçados com elementos sacerdotais.

${ }^{7}$ Cf. SEEBASS, H. Nm XI, XII und die Hypothese des Jahwisten, p. 214-223; citado por: DE PURY, A.; RÖMER, Th. O Pentateuco em questão: Posição do problema e breve história da pesquisa. In: O Pentateuco em questão, p. 71. 
mais tardia do que tradicionalmente era considerado. Segundo os estudos do modelo de Münster proposto por P. Weimar e E. Zenger, o Pentateuco apresenta esta evolução: antes do ano 700 a.C., havia a história primitiva e os círculos narrativos orais, os quais, a partir de 650 a.C., serviram para formar a obra histórica de Jerusalém, equivalente ao hexateuco (Gn 2,4b-Js 24). Depois do exílio, em 586 a.C., esta história sofreu outra elaboração com o acréscimo do livro da aliança (Bundesbuch), do livro do Deuteronômio (Dt 12-26), e de algumas tradições sobre a monarquia, formando assim a grande obra histórica exílica que seria a história deuteronomista (Gn 2,4b-2Rs 25). Depois de 520 a.C. foram acrescentados os escritos sacerdotais (Gn 1,1- Lv 9,24. Dt 34,8) que completaram o que Zenger chamou de a grande obra histórica pós-exílica (Gn 1,1-2 - 2Rs 25). O Pentateuco ficou pronto pouco depois, por volta de 400 a.C. ${ }^{8}$ Os autores do modelo de Münster não negam a existência de tradições e leis antigas. Porém o material outrora datável no tempo de Salomão (como a antiga história Javista, conforme os estudos de G. Von Rad) agora tomou forma escrita a partir de 650 a.C até o tempo do exílio de Babilônia. A maior parte das tradições foram escritas pouco antes do exílio e no exílio, quando se formou a história deuteronomista (Eneateuco). Mas a grande obra histórica pós exílica como propõe Zenger, ganhou forma junto com a obra sacerdotal depois de 450 a.C.

\section{A questão da época das tradições que formaram Nm 16-17}

Em relação a Nm 16-17 esta mudança na datação das tradições levou os autores a situar a redação final do texto no fim da época persa e até mesmo no início do período grego ${ }^{9}$. Com efeito as tradições de Datã e Abiram, que eram atribuídas no passado a uma antiga tradição do tempo de Salomão (Javista) são deslocadas para um período bem posterior depois do ano 650 a.C, até o tempo do exílio. De consequência parece claro, que ela seja tradição pré-sacerdotal. Não se nega que parte dessa tradição possa ter raízes mais antigas na fase de transmissão oral. Como veremos na pesquisa, é mais provável que a tradição de Datã e Abiram seja tradição com forte influência do deuteronômio e da tradição deuteronomista (F. Crüsemann, E. Blum). Também parece claro, para E. Zenger e E. Blum, que o sacerdotal vem depois do deuteronômio na

\footnotetext{
${ }^{8}$ Para uma visão sintética dos modelos e Münster e Heidelberg cf. COUTO, A. Pentateuco: caminho da vida agraciada. Lisboa: Universidade Católica Editora, 2005, pp.51-56.

${ }^{9}$ Cf. ARTUSO, V. As revoltas contra Moisés e Aarão em Nm 16-17, p. 384.
} 
composição do Pentateuco ${ }^{10}$. Dessa forma, justifica-se a caracterização dessa tradição antiga como pré-sacerdotal, sem necessariamente uma especificação mais precisa do tempo de sua redação.

Segundo outros autores anteriores aos estudos de E. Zenger, por suas características o antigo "Javista" ao qual é atribuída a revolta de Datã e Abiram, seria uma fonte exílica ou pós-exílica colocada em relação com a historiografia deuteronomista (Schmid, Rose, Van Seters, e Schmitt) ${ }^{11}$. ou ainda haveria um Javista depois do Deuteronômio e do Deuteronomista ${ }^{12}$. M. Rose, comparando textos da história deuteronomista (Dt 1-3; Js) com textos do tetrateuco referentes às mesmas tradições (Js 2-6 com Ex 16,35; Nm 22,22-35; Ex 3,1-5; Js 9-10 com Gn 34), chega à conclusão de que os textos ditos Javistas pressupõem os textos da história deuteronomista. Segue-se que o tal documento Javista deveria ser datado mais tarde que a primeira edição da historiografia deuteronomista ${ }^{13}$. Segundo Schmid que admite a existência de uma fonte J (Javista), mas esta deve ter sido composta no exílio.

Em relação a Nm 16-17, F. Ahuis ${ }^{14}$, tem uma posição mais conservadora. Além de reconhecer a tradição Javista mais antiga, para a revolta de Datã e Abiram reconhece a existência de uma camada deuteronomista e até pós-deuteronomista na história da revolta de Coré. Nessa reflexão, se supormos que o antigo Javista é anterior ao deuteronômio e às camadas deuteronomistas, e o Sacerdotal posterior como tradicionalmente é aceito, tal teoria demonstra porque Dt 11,6 menciona a morte de Datã e Abiram mas não a morte de Coré. Justamente porque a tradição de Datã e Abiram é anterior à tradição de Coré que é Sacerdotal. A hipótese em parte explicaria certas mudanças de cena em nosso texto um tanto estranhas à primeira vista (Nm 16,1-11 para 16,12-15). O texto de Nm 16-17 seria nesse caso, como diziam os comentários mais antigos, fruto de uma junção mal integrada de diferentes tradições (B. Gray). F. Ahuis de fato parece supor a existência de um Javista, anterior à tradição deuteronomista remontando ao tempo dos reis. Esta posição, quanto à datação das etapas de composição é superada pelo modelo de E. Blum. Esse autor descarta a exis-

\footnotetext{
${ }^{10}$ Cf. ZENGER, E. et al. Einleitung in das Alt Testament, Berlin, 2004, p. 105 passim.

${ }^{11}$ Cf. DE PURY, A.; RÖMER, T. O Pentateuco em questão: Posição do problema e breve história da pesquisa. In: O Pentateuco em questão, p. 72.

${ }^{12}$ Cf. SKA, J. L. Introduzione al Pentateuco, pp. 155-156; RÖMER, T. L'Histoire Redactionnelle des Premiers livres de la bible. Estúdios Bíblicos 62, p.138.

${ }^{13}$ Cf. DE PURY, A.; RÖMER, T. O Pentateuco em questão: Posição do problema e breve história da pesquisa. In: O Pentateuco em questão, p. 66.

${ }^{14}$ Cf. AHUIS, F. Autorität im Umbruch. Stuttgart, Calver Verlag, 1983, p. 72.
} 
tência do Javista. Segundo ele, teria existido uma antiga tradição oral sobre Moisés bem mais recente (Moseerzälung - 700 a.C) que deu origem à composição deuteronômica (KD -Dt, Js, Sm, Rs) no fim do séc. VI a.C. Nessa composição foi juntada a obra histórica deuteronomista (DtrG - Deuteronômio, Josué, Samuel, Reis) que teve uma origem independente da tradição de Moisés sendo composta no tempo do exílio.

Depois da mencionada composição deuteronômica $(\mathrm{KD})$ que pode ser situada no fim do séc. VI a.C, o texto teve mais um aumento com composição Sacerdotal por volta de 500 a.C. (Priesterliche Komposition - KP), a qual se formou juntando a composição deuteronômica, a chamada história primitiva (Urgeschichte - 700 a.C) e outras antigas tradições. Esta fase da composição sacerdotal como referimos ocorreu por volta de 500 a.C. ${ }^{15}$ recebendo outros acréscimos. Segundo E. Blum não existem fontes paralelas e independentes no Pentateuco, no sentido da hipótese documentária, mas duas composições tardias muito próximas que recolheram e elaboraram tradições mais antigas: uma composição deuteronômica (KD) posterior ao livro do deuteronômio e uma "composição sacerdotal" (KP), que também pressupõe tradições antigas, datável da época persa ${ }^{16}$.

Conforme essas pesquisas de E. Blum, apenas na época pós-exílica é que a composição sacerdotal estabeleceu um vínculo entre a história patriarcal e o resto do Pentateuco, que, como vimos anteriormente, incluía também a composição deuteronomista ${ }^{17}$. Isso significa que o material, outrora atribuído a um Javista Salomônico, revela características deuteronomistas de uma

${ }^{15}$ Cf. BLUM, E. Studien zur Composition des Pentateuch,Berlin \& New York, Walter de Gruyter, 1990, pp. 160-220.

${ }^{16}$ Cf. BLUM, E. Studien zur Composition des Pentateuch, citado e comentado in: GARCIA LOPES, F., O Pentateuco, p. 43. Esse modelo alternativo que E. Blum propõe à teoria documentária clássica é considerado muito valioso por E. W. NICHOLSON (Journal Study of the Old Testament, n. 79, p. 139); Para R. ALBERTZ (História de la religión de Israel II. Valladolid, Editorial Trotta, 1999, pp. 617-619) o modelo de Blum é o que explica de maneira mais convincente a origem do Pentateuco. Por outro lado D. M. CARR, o qualifica de "desenfocado e antiquado" e "frequentemente inexato e injusto" (Journal Biblical Literature 117 (1998), p. 723). (As apreciações e notas sobre os estudos histórico-críticos de R. Rendtorff e E. Blum encontram-se in: GARCIA LOPES, F. O Pentateuco, p. 41-43). Observamos que os novos modelos de estudos histórico-críticos, recebem apreciações positivas e também críticas duras (Uma apreciação de algumas obras atuais sobre o Pentateuco encontra-se in: SKA, J. L. Res Bibliograficae - Le Pentateuque, état de la recherche à partir de quelques recentes "Introductions" Biblica 77 (1996) fasc. 2, pp. 245-265; Id. Le Pentateuque à l'heure de ses usagers. Biblica 87(2006) fasc. 1, pp. 98-110).

${ }^{17}$ Cf. DE PURY, A.; RÖMER, T., O Pentateuco em questão: Posição do problema e breve história da pesquisa. In: DE PURY, A. O Pentateuco em questão, p. 69; GARCIA LOPES, F. O Pentateuco, p. 49-55. 
época bem mais tardia (no mínimo no final do séc. VI a.C seguindo o modelo de Blum, e depois de 650 seguindo o modelo de Zenger). Diante disso, a sigla J (Javista) não mais é mencionada em estudos recentes do Pentateuco. Conforme o modelo de Blum, como também de Zenger, pode-se falar da existência de uma tradição pré-sacerdotal em nosso texto (que seria nesse caso a história da revolta de Datã e Abiram) sem afirmar uma datação precisa ${ }^{18}$.

Encontramos inspiração no modelo de Zenger, e em parte no modelo de Blum, para levantar uma hipótese mais aproximada das etapas de composição do nosso texto de Nm16-17. Se no passado era consenso que a tradição de Datã e Abiram fora atribuída a uma tradição escrita, quem sabe no tempo de Salomão (Javista de G. Von Rad), seguindo as pesquisas recentes, devemos deslocar sua origem escrita em tempos próximos do exílio, e até mesmo no fim do exílio de Babilônia conforme E. Zenger ${ }^{19}$. O autor sacerdotal, no período do pós-exílio, após 520 a.C, utilizou-se dessas tradições de revolta no deserto, unindo-as com a tradição da revolta de Coré que encabeçou um grupo de duzentos e cinquenta homens que protestavam contra as prerrogativas religiosas da tribo de Levi. Depois da composição da grande obra histórica pós-exílica (eneateuco-), no tempo de Esdras e Neemias, por volta de

\footnotetext{
${ }^{18}$ Cf. SCHORN U. Rubeniten als exemplarische Aufrürer in Num 16/Deut.11. Beiträge Zeitschrift für die Alttestamentliche Wissenschaft, vol. 294 (2000) p. 252.

Como a tradição sacerdotal é situada no pós-exílio, para esse autor, vem considerada como um divisor de águas. A partir dela, ele se refere às outras fontes, preferindo falar de tradições pré-sacerdotais e pós-sacerdotais sem identificá-las e situá-las historicamente. Parece haver um consenso sobre o tempo da tradição sacerdotal com origem no exílio e concluída na época pós-exílica. A questão levantada é se a tradição $P$ é uma obra primitivamente independente ou deveríamos ver em P uma camada redacional final. (cf. DE PURY, A.; RÖMER, T., O Pentateuco em questão: Posição do problema e breve história da pesquisa. In: DE PURY, A. O Pentateuco em questão, p. 75). Diante disso a posição de se referir às outras fontes em relação à fonte sacerdotal, como pré-sacerdotal ou pós-sacerdotal é ainda frágil, porém é a mais preferível entre os autores. J. L Ska concorda com o abandono de um documento Javista e Eloísta, mas é convencido da existência do sacerdotal, discordando daqueles que chegam a negar a existência do escrito sacerdotal. Segundo ele, o escrito sacerdotal não é uma simples coleção de relatos justapostos, porque possui um estilo próprio (não apenas um vocabulário próprio) e uma visão unificada de toda a história das origens. Esses elementos não se encontram nos documentos Javista e Eloísta da teoria documentária (cf. SKA, J. L. Res Bibliograficae: Le Pentateuche à l'heure de ses usages. Bíblica 87 (2006) fasc. 1, p. 108-109).

${ }^{19}$ Cf. ZENGER, E. et. al. Einleitung in das Alte Testament, Stuttgart; Berlin; Köln, Kohlhammer Studienbücher Theologie, 2004, p. 120. Nesta quinta edição publicada em 2004, E. Zenger em parte modifica o seu modelo de explicação da formação do Pentateuco em relação à primeira edição de 1995.
} 
400-350 a.C..$^{20}$, o autor reelaborou a tradição existente com a intenção de estabelecer a distinção entre sacerdotes filhos de Aarão e Levitas, confirmando a supremacia do sumo-sacerdócio de Aarão (Nm 17,1-5; 17,6-28). Assim foi formada uma história de revolta fracassada em Nm 16-17, com o objetivo de dar sustentação teológica à classe sacerdotal em conflito com os líderes favoráveis a um governo mais democrático. Portanto nosso texto compõe-se de uma tradição pré-sacerdotal e uma tradição sacerdotal composta em várias etapas até chegar a sua forma final.

\section{Aplicação da crítica das fontes em Nm 16-17}

Lembramos mais uma vez que, na questão das fontes, permanece ainda um quadro de incertezas, "faltam critérios mais sólidos para decidir se determinados textos pertencem a um estrato ou a outro e se são mais ou menos antigos" ${ }^{\prime 21}$. Por isso a proposta dos estudiosos sobre a época de composição das tradições, outrora tida como segura, para muitos textos do Pentateuco, é hoje mais genérica e indicativa.

Mais com o objetivo de informar, relatamos a seguir uma síntese da história da crítica de fonte de Nm 16--17. O leitor poderá constatar que a pesquisa pouco evoluiu no sentido de apresentar um novo consenso que viesse a suprir o sistema de J. Wellhausen.

$\mathrm{O}$ que realmente alterou foi a nomenclatura e a data de algumas fontes clássicas. Praticamente todos os comentários e artigos sobre Nm 16--17, como

\footnotetext{
${ }^{20}$ As moedas com a inscrição yehudîm, mostram para a última fase do domínio persa, uma independência maior da província do templo, a qual não era mais representada por um governador, mas tão somente pelo sumo-sacerdote (cf. BARAG, B. Some notes on a silver coin of Yohanan the High Priest. Biblical Archaelogist 48 (1985) pp.166-168; MAIER, I. Entre os dois Testamentos, São Paulo, Loyola, 2005, pp. 50-51). No governo persa de Artaxerxes I, até 425, em Judá, o sumo sacerdote era Joanã (Ne 12,11.22) (cf. BO REICKE, I. História do tempo do Novo Testamento. São Paulo, Paulus, 1996, p. 33). Esse dado revela que a forma final de nosso texto mostrando o conflito de levitas com os sacerdotes, pode ser do período final do império persa. Outros autores admitiram a liderança do sumo-sacerdote apenas no período helenista (cf. LAPERROUSSAZ, $\mathrm{S}$. Le regime théocratique Juif a-t-il commencé à l'époque perse, ou seulement à lépoque hellénistique? Semítica 32 (1982) pp. 93-96). Esses clãs sacerdotais de Jerusalém se consideravam descendentes de Sadoq (1 Rs 2,35). Sua vanguarda aristocrática eram os oníadas, que justamente no fim da época persa e na época helenística ocupavam hereditariamente o cargo de sumo sacerdote. Essa camada sacerdotal foi decaindo a partir do início da época dos Macabeus (cf. MAIER, I. Entre os dois Testamentos, p. 271; LIVER, J. The sons of Zadok the Priest in the Dead Sea Scrolls, Revew of Qumran 6 (1967) pp. 3-30).

${ }^{21}$ GARCIA LOPES, F. O Pentateuco, p. 276.
} 
veremos a seguir, fazem um estudo diacrônico dentro dos moldes da interpretação tradicional do Pentateuco. Nossa postura, diante da análise diacrônica do texto, não se distanciou da opinião mais comum da existência de duas ou três mãos que podem ter trabalhado em Nm 16--17. O que muda conforme novos modelos de análise diacrônica é a data de determinadas tradições e o entendimento da composição do pentateuco conforme as propostas da hipótese dos fragmentos ou dos complementos como parece ser o modelo de Blum e Zenger. Diante disso coloca-se em questão a demasiada preocupação de delimitar as fontes ou estratos literários do texto, como se fosse uma "colcha de retalhos mal costurada". A composição final de nosso texto mostra uma coerência interna e um sentido unitário final como um enredo bem construído. A análise mais atenta da forma na segunda parte da pesquisa, trará novos elementos em favor da unidade do nosso texto.

Com base no método histórico-crítico, estudando as diferentes tradições de Coré, Datã e Abiram (cf. Dt 11,6; S1 106,16-17; Nm 27,3), os críticos mostraram que a história da revolta de Datã e Abiram, em Nm 16-17, inicialmente era independente da história de Coré $^{22}$. Em determinado estágio da tradição, estas histórias foram reunidas de uma forma muito mecânica, com algumas tentativas frustradas de harmonização $\left(\mathrm{Nm} \mathrm{16,24.} \mathrm{27.32)}{ }^{23}\right.$. Isso em parte explica a existência de rupturas e tensões no texto final. Assim, desde o advento da crítica literária clássica ${ }^{24}$ até meados da década de oitenta, prevaleceu um consenso quase sem questionamento entre os estudiosos, de que a história deve ser atribuída a três fontes ou camadas literárias, com algumas variações em detalhes menores.

$\mathrm{O}$ texto é composto de uma antiga fonte pré-sacerdotal, que eles chamavam de Jeovista (JE) ${ }^{25}$ : 16,1b.2a.12-15. 25. 26b. 27b-32a.33-34. Esta

${ }^{22}$ Cf. MAGONET, J. The Korah Rebellion. Journal Study of the Old Testament 24 (1982) p. 6.

${ }^{23}$ Cf. GRAY, G. B. A Critical and Exegetical Commentary on Numbers. Edinburgh, T.Clark Limited, 1956, p. 187; DAVIES, E. W. Number. London, William B.Eedmans Publishing Company, 1980, p. 163. Estudos mais recentes, já apresentam uma visão mais positiva da composição do texto (E. Blum; F. Crüsemann; B. A. Levine).

${ }^{24} \mathrm{~A}$ partir da segunda metade do século XIX e início do século XX, surgiram estudos e comentários detalhados do livro dos Números que nortearam as pesquisas. Destacamos Keil (1869), Dillmann (1886), Paterson (1990), Gray (1903), Baentsch (1903), McNeile (1911).

${ }^{25}$ Para J. Wellhausen (Die Composition des Hexateuchs. 3 ed, 1899, p. 102-106; 240-242) e A. Kuenen (Theologisch Tisjdschrift, n. 12, 1878. p. 139-162), os primeiros a basearem seus estudos na hipótese documentária, o texto compõe-se de elementos J, E, e P (Q). A história de Datã e Abiram, a mais antiga, segundo eles e outros críticos (H. Holzinger, B. Gray, H. Gressman), comporta elementos Javistas e Eloístas (Todos esses autores são citados por: LIVER, J. Qorah, 
história conta como os rubenitas Datã e Abiram se revoltaram contra a autoridade civil de Moisés e foram punidos. A seguir vem a fonte sacerdotal que compõe a maior parte do texto: 16,1a. 2b.3-7.18-24.26a.27a.35.17,6-15. Esta fonte conta a história de Coré, filho de Levi, líder da revolta de um grupo de duzentos e cinquenta homens, contra os privilégios de Moisés e Aarão. Estes, quando ofereceram incenso a YHWH, foram mortos com o fogo divino $(16,35)$. A fonte sacerdotal recebeu acréscimos provavelmente na redação final com alguns suplementos: 16,1a.7b-11.16-17. 32b;17,1-5; 16-28. Esta fonte relata como alguns levitas protestaram contra Aarão ${ }^{26}$. Há dúvidas entre os estudiosos sobre quais os versículos que pertenceriam à tradição sacerdotal mais antiga, e

Dothan and Abiram. Scripta Hierosolymitana 8 (1961) p. 193). Dada a dificuldade de distinguir estas duas fontes, o próprio J. Wellhausen preferia a sigla JE (Jeovista), que era uma obra literária e redacional construída a partir de duas fontes principais J e E. (Cf. DE PURY, A.; RÖMER, T., O Pentateuco em questão: Posição do problema e breve história da pesquisa. In: DE PURY, A. $O$ Pentateuco em questão, p. 30). Os comentários utilizam a sigla JE (T. R. Ashley; G. J. Wenham; Baruch A. Levine), ou simplesmente J (E. W. Davies), sem entrar na discussão se é possível separar dois estratos distintos $\mathrm{J}$ e E. Bom número de estudos recentes, praticamente não reconhecem uma fonte Javista ou mesmo Jeovista. Simplesmente os comentários relatam a existência de uma fonte pré-sacerdotal sem definir uma época precisa de sua origem (cf. GARCIA LOPES, F. $O$ Pentateuco, p. 43-44.276). No estado atual da pesquisa, melhor seria não utilizar a sigla J., mas referir apenas uma fonte pré-sacerdotal. No entanto, como estamos citando autores anteriores às atuais mudanças de rumo na teoria documentária, ou mais recentes que ainda são vacilantes diante dos avanços da pesquisa, teremos de usar algumas vezes a sigla JE (Jeovista) ou J (Javista). Por haver certo consenso da tradição sacerdotal que ainda parece segura tendo sua composição final no pós-exílio, outras fontes supostamente mais antigas são referidas em relação a esta fonte como pré-sacerdotais (Uma reflexão recente em torno da existência do escrito sacerdotal e sua importância encontra-se in: SKA, J. L. Res Bibliograficae: Le Pentateuque à l'heure de ses usagers. Bíblica 87, fasc.1, pp. 106-110).

${ }^{26}$ Cf. WENHAM, G. J. Números, Introdução e comentário. São Paulo, Edições Vida Nova \& Mundo Cristão, 1985, p. 48; GRAY, G. B. A Critical and Exegetical Commentary on Numbers p. 187-189; COATS, W. G. Rebellion in the Wilderness, Nashville, Abingdon Press, New York, 1968, pp. 156-184; FRITZ, W. Israel in der Wüste, Marburg, N.G. Elwer Verlag, 1970, pp. 24-25.86-89; BUDD, P. Numbers, Waco \& Texas, General Editors, Word Books, 1984, pp. 181-186; COATS, G. W. Rebellion on the Wilderness, p. 156-170. Esses autores apresentam poucas variações. Outros apresentam modificações mais significativas: AHUIS, F. Autorität im Umbruch. Stuttgart, Calver Verlag, 1983, pp. 72-73; AURELIUS, E. Der Fürbitter Israels. Stockholm, (s.n.) 1988, pp. 185-197; SCHORN, U. Rubeniten als exemplarische Aufrührer in Num 16f/Deut 11. Beiträge Zeitschrift für die alttestamentliche Wissenschaft 294 (1988), p. 252; LUX, R. Und die Erde tät ihren Mund auf... In: VIEWEGER, D.; WASCHKE, E. J. Beiträge zur Theologie und Exegese des Alten Testaments (1995), p. 188. A nomenclatura das fontes sofreu mudanças. Os últimos autores aqui citados (U. SCHORN, R. LUX) não utilizam a fonte Javista. Eles também chamam de pré-sacerdotais as fontes mais antigas de Nm 16-17. 
quais de fato seriam da última camada sacerdotal ${ }^{27}$. Isso explica porque entre os autores há variações em certos detalhes na distribuição das fontes ${ }^{28}$.

A seguir temos um breve inventário dos principais autores quanto às fontes de $\mathrm{Nm} 16$ e $17^{29}$. Eles concentraram atenção maior sobre Nm 16,1-35, que possui uma composição mais complexa. Quanto a Nm 17,1-28, é um texto sacerdotal que não apresenta maiores problemas. Pequenas variações nas siglas clássicas para identificar as fontes, serão explicadas quando necessário entre parêntesis.

1- A. Kuenen (1869 e 1878) - Foi o primeiro a introduzir a sigla P, para a fonte Sacerdotal. Distinguia a fonte Sacerdotal chamada $\mathrm{P}$ em diferentes camadas (P2: Sacerdotal n. 2, P3: Sacerdotal n. 3). Assim para Nm 16 propunha esta divisão: P2: 16,1*30.2*.3-7.13-15a.19-24.27a.35; P3 od. P4: 16,1*.8-11.16-18.

\section{2- J. Wellhausen (1899)}

J (Javista): Nm 16,12-24.15b;

JE (Jeovista: J+E): 16,3-5.15a.23-24;

Q (Quattuor ${ }^{31}$, corresponde a fonte Sacerdotal- P): 16,8-11.16-22.35 R: $16,1.2 .6 f$

$\mathrm{O}$ autor apresentou também outra alternativa:

JE: $16,1.12-14.15 b \cdot 25 \cdot 26.27 b-32 a .33$

Q: 16,2-7.19-24.27a.

"Diaskeuast": 16,8-11.16-18.32b

${ }^{27}$ Cf. AHUIS, F. Autorität im Umbruch, p. 73; DAVIES, E. W. Numbers. London, William B. Eedmans Publishhing Company, 1980, p. 163; NOTH, M. Numbers. London, SCM Press, 1968, p. 122.

${ }^{28}$ Cf. ZWICKEL, W. Räucherkult und Räuchergerät. Fribourg, Editions Universitaires, 1990, pp. 291-297.

O autor apresenta esta composição, limitando-se a Nm 16,1-17,5: Teríamos uma história mais antiga de Datã e Abiram (Nm 16,1.2a 12-15.25f.27b.28-31.32a.33a), construída sobre a história dos

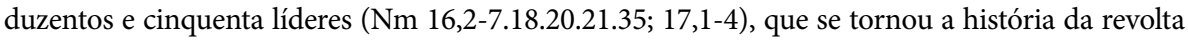
de Coré (Nm 16,1.8.9-11.16f.19.22.23.24.27.32-34; 17,5). Vemos que, diferente dos outros, ele não utiliza os nomes das fontes clássicas.

${ }^{29}$ Parte desse inventário até 1983 encontra-se in: AHUIS, F. Autorität im Umbruch, p. 73.

${ }^{30} \mathrm{Em}$ todos os autores citados, o asterisco $\left.{ }^{*}\right)$ indica que o versículo possui mais de uma fonte.

${ }^{31} \mathrm{Na}$ sua obra Die Compositio des Hexateuchs 1893 (1876-1877), J. Wellhausen qualifica a fonte Sacerdotal com a sigla Q (Quattuor) em razão das quatro alianças existentes no código Sacerdotal: com Adão, Noé, Abraão e Moisés. Em outra obra, Prolegomena to the history of Israel (1883), ele qualifica a fonte Sacerdotal de Priestercodex com a letra P. O código sacerdotal, segundo ele pertence à época pós-exílica.

${ }^{32}$ As propostas de Kuenen e Wellhausen, nesta forma, exceto as explicações das siglas, são tomadas de AHUIS, F. Autorität im Umbruch, p. 73. 
3- G.B. Gray (1903) - JE: 16,1f*.12-15.25.26b.27b-32a.33.

Pg (Obra sacerdotal de base: priester Grund)16,1f*.3-7.18-23.26a.27a.35; 17,6-15.

Ps (Suplemento da obra sacerdotal: priester Suplement)16,8-11.16f;17,1-533.

4- S. R. Driver (1913) - A revolta de Coré, Datã e Abiram é uma confirmação das prerrogativas sacerdotais da tribo de Levi. Nm 16-17 é composto por duas, senão três narrativas combinadas: P 16,1a 2b-7 ${ }^{\mathrm{a}}$. (7b-11). (16-17). 18-24. $27^{\mathrm{a}}$. 32b. 35. (36-40). 41-50 e capítulo 17; JE 1b-2a . 12-15. 25-26. 27b-34. Os versículos entre parêntesis poderiam ser segundo o autor a terceira narrativa aí combinada como suplemento da fonte Sacerdotal ${ }^{34}$.

5- G. Von Rad (1938) - Pa (Obra sacerdotal mais antiga): 16,1*.2*.3-4.5*. 6-7a.18.23f.35

$\mathrm{Pb}$ (Suplemento da obra sacerdotal): $16,1 * .2 * .5^{*} .7 \mathrm{~b}-11.16 \mathrm{f} .19-22$.

6- W. Rudolph (1938) - J: 16,12-15.26f. 27b-34.

Pg: 16,3-7a.18-27a.35.

Ps: $16,7 b-11.16 f$.

R: (posterior reelaboração com acréscimos) 16,1 f5 $^{35}$.

7- M. Noth (1962) - J: 16,1*.12-15.24*.25f.27b-32a.33f

Ps1: $16,1^{*} .2-7^{\mathrm{a}} .35 ; 17,6-15$

Ps2: 16,7b-11.16-24aba.27a.32b; 17,1-5.16-26.

8- A. H. J. Gunneweg (1965) - J: 16,1b.2a*.12-15.25.26.27b.32a.33ab*.34

P: $16,1 a^{*} .2 a^{*}$ b. $3-7 \mathrm{a} ; 17,6-15$

Ps $16,1 a^{*} .7 \mathrm{~b} \cdot 8-11 \cdot 16 \cdot 17^{36}$.

9- G. W. Coats (1968) - J: 16,1b-2aa.12-15.24abb*-26.27abb-31

Pg 16,1aa.2aBa-7a.18-24aba.27aa.32-35

Ps 16,7b.8-11.16-17; 17,1-5.6-15.16-26 (27-28)

\footnotetext{
${ }^{33}$ Cf. GRAY, G. B. A Critical and Exegetical Commentary on Numbers, p. 188.

${ }^{34} \mathrm{Cf}$. DRIVER, S. R. Introduction to the Literature of the Old Testament. New York, Charles Scribner's sons, 1950, p. 63.

${ }^{35}$ RUDOLPH, W. Der Elohist von Exodus bis Josua, Berlin, Alfred Töpelmann, 1938, p. 81.

${ }^{36}$ Textos na forma citada por AHUIS, F. Autorität im Umbruch, p. 73.

${ }^{37}$ Cf. COATS, W. Rebellion in the Wilderness, p. 157-162.
} 
10- V. Fritz (1970) - J: 16,12-14.25.27b.28-31.33aba.34

P $16,1^{\mathrm{a}} .2 .3-7^{\mathrm{a}} .18^{*} 23.24 * .27^{\mathrm{a} *} .35$

R: $16,7 b-11.15 .16 f .18^{*} .19 .20 .21^{38}$.

11- F. Ahuis (1983) - J: 16,12-15*.25.27b-31.33a.

P: $16,1^{\mathrm{a} *} 2^{\mathrm{a} *}-5^{\mathrm{a} *} \cdot 6^{\mathrm{a}} \cdot \mathrm{b}^{*} \cdot 7^{\mathrm{a}} \cdot 18^{\mathrm{a}} \cdot \mathrm{b}^{*} \cdot 35^{\mathrm{a}} 17,7-13$.

DtrT (Tradição deuteronomista) $16,1^{\mathrm{a} *} \cdot \mathrm{b} \cdot 2^{\mathrm{a} *} \cdot 5^{\mathrm{a} *} \cdot \mathrm{b} .6 \mathrm{~b} * 7 \mathrm{~b}-11$.

13a*.14a*16+17.18b*. 19-24. 26-27 $.32 .33 b-34.35 b .17,6.14+14$

Pós Dtr (Pós deuteronomista) em estilo de P: 17,1-5.16-2839.

12- P. J. Budd (1984) - J: 16,1b.2a. 12-15.21.25. 27b-31,33a. com elaborações em 16,32a 3 3ba, 34. P mais antigo: 16,2b.4-7.18.35.17,6-15.16-26. P na redação final: 16,1a. 3.8-11.16-17.19-24.26-27 ${ }^{\mathrm{a}} \cdot 32 \mathrm{~b} .33 \mathrm{bb} \cdot 17,1-5^{40}$.

13-W. Zwickel (1990) - Sem mencionar o nome das fontes, a história seria formada de uma mais antiga história de Datã e Abiram que abrange $\mathrm{Nm}$ $16,1 \mathrm{a} * .2 \mathrm{a} \cdot 12-15 \cdot 25 \mathrm{f} \cdot 27 \mathrm{~b} \cdot 28-31.32^{\mathrm{a}}$. $33^{\mathrm{a}}$ da qual faz parte a história dos 250 líderes $(16,2 *-7.18 .20 .21 .35 ; 17,1-4)$ e que foi completada mais tarde com a história da revolta de Coré $\left(16,1 * .8 .9-11.16 f .19 .22 .23 .24 .27 .32-34 ; 17,5^{41}\right.$.

14- B. A. Levine (1993) - JE: Nm 16,1-2 (reescrito por P). 12-15, 25-34 com várias inserções sacerdotais. P: Nm 16,3-11, 16-24, v. 35 e 17,1-28.

15-U. Schorn (2000) - Para ele a história é formada de uma tradição pré-sacerdotalque inclui a história Datã eAbiram (16,1b*.2aa.12-14.25.26*.27b.32a.33a. ba.34). Depois vem a tradição sacerdotal da revolta dos 250 líderes (16,2ab. (b?).3.4.5*.6a.ba.7a.18*.35a.ba;17,6-10.11*.12.13.27.28b) que recebeu um alargamento sacerdotal tardio com elementos de Coré como levita $\left(16,1^{\mathrm{a}}\right.$. $5^{*} .6 \mathrm{bb} .7 \mathrm{~b} .11 .16 .17 .18 \mathrm{~b} *$. 19.23.24*.27**.35ab;17,1.2aa.b3a.4.5bb) e que foi completada com a última redação em 16,15.24*. 26*27*.28-31.32b.33bb. A tradição sacerdotal é a linha divisória, a partir da qual podem ser interpretadas outras fontes ${ }^{43}$.

${ }^{38}$ Cf. FRITZ, V. Israel in der Wüste, p. 24-26.

${ }^{39}$ Cf. AHUIS, F. Autorität im Umbruch, p. 72.

${ }^{40}$ BUDD, P. J. Numbers, p. 184.

${ }^{41}$ ZWICKEL, W. Räucherkult und Räuchergerät, p. 291-297.

${ }^{42}$ LEVINE, B. A. Numbers 1-20. New York \& London, Doubleday, 1993, p. 405.

${ }^{43}$ SCHORN, U. Rubeniten als exemplarische Aufrürer in Num 16f/Deut.11. Beiträge Zeitschrift für die Alttestamentliche Wissenschaft. vol. 294, p. 252. 
O quadro acima revela o consenso geral sobre o caráter compósito de Nm 16-17 com três camadas literárias (a maioria dos autores) ou no mínimo duas (B. A. Levine). A tradição de Datã e Abiram encontra-se melhor conser$v a^{44}{ }^{44}$ e pode razoavelmente demarcável, pois não menciona Aarão, nem contém referência aos levitas, ou outros elementos próprios da tradição sacerdotal. Os nomes Datã e Abiram foram inseridos nas passagens sacerdotais (P), e os textos de Coré foram entrelaçados com os textos da tradição de Datã e Abiram

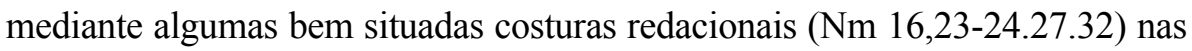
quais aparece clara a intenção de compor uma só história ${ }^{45}$.

Embora a maioria dos autores considere, por exemplo, Nm 16,12-15 como peça unitária da tradição pré-sacerdotal, alguns autores veem uma inserção sacerdotal em 16,15 como obra do último redator (V. Fritz, U. Schorn, S. Schmidt). A tradição sacerdotal não é uniforme, pois recebeu complementos tardios e sofreu intervenções que mostram uma expansão do texto, e algumas vezes a intenção de unir as duas histórias (cf. 16, 23-24.27.32). Talvez, também por isso, como referimos acima, entre os autores há certas discordâncias na atribuição de alguns versículos ou partes de versículos, se pertencem à tradição sacerdotal mais antiga ou seriam obra da composição final do autor sacerdotal. É o caso da complexa composição de 16,1-3 em que eles discutiram se Coré deve ser atribuído à tradição sacerdotal ou poderia ser uma inserção tardia dessa mesma tradição. Mais especificamente, se Coré pertence à versão pré-sacerdotal (JE) como líder de um grupo de leigos, ou pertence à versão sacerdotal $(\mathrm{P})$ como líder de um grupo de levitas. F.Ahuis ${ }^{46}$ trouxe à tona essas questões, deixando-as abertas a estudos posteriores. S. Lehming ${ }^{47}$ representa uma resposta extrema à pergunta sobre a que estratos literários se deva atribuir a composição de Nm 16-17, e chegou a verificar oito estratos ou camadas literárias. $\mathrm{O}$ texto mais primitivo seria a história dos duzentos e cinquenta homens que se recusaram a participar da tomada da terra ${ }^{48}$. Somente numa segunda etapa, Datã e Abiram são mencionados como aqueles que se revoltam contra a exigência de exclusividade dos levitas como sujeitos da revolta em

\footnotetext{
${ }^{44}$ Cf. BUDD, P. J. Numbers, p. 180.

${ }^{45}$ Cf. LEVINE, B. A. Numbers 1-20, p. 405-406.

${ }^{46}$ Cf. AHUIS, F. Autorität im Umbruch, p. 25.

${ }^{47}$ Cf. LEHMING, S. Versuch zu Num 16. Zeitschrift für die alttestamentliche Wissenschaft n. 74 (1962), p. 320.

${ }^{48}$ Cf. LEHMING, S.Versuch zu Num 16. Zeitschrift für die alttestamentliche Wissenschaft, n. 74, p. 301-303.
} 
$16,2-3 \mathrm{a}^{49}$. F. Ahuis ${ }^{50}$ vê a proposta de oito camadas literárias de S. Lehming como um argumento a favor do crescimento sucessivo do conteúdo de $\mathrm{Nm}$ 16 ao longo da transmissão oral. Atualmente os autores definem três tipos de elementos em 16,1-3: uma tradição antiga de Datã e Abiram, elementos sacerdotais sobre os duzentos e cinquenta líderes e elementos mais tardios atribuídos aos autores que entrelaçaram as duas tradições precedentes ${ }^{51}$. Na última fase redacional, o levita Coré teria sido incluído. L. Schmidt ${ }^{52}$ sugere quatro estágios redacionais: a) um relato pré-sacerdotal referente a Datã e Abiram; b) um relato sacerdotal sobre os 250 líderes; c) uma releitura sacerdotal introduzindo o personagem Coré; d) uma costura redacional final. Segundo ele, Coré seria anterior à última etapa de composição do texto, durante a qual teria sido efetuada a fusão do relato pré-sacerdotal e sacerdotal.

Feita essa resenha histórica, observamos então mudanças na pesquisa. Admite-se atualmente o caráter compósito do texto, com diferentes fontes ou tradições, porém com maiores dificuldades de identificá-las nos detalhes, devido também ao aparecimento de modelos variados e até díspares. Há mudanças e adaptações na linguagem, como é o caso dos nomes das siglas clássicas. A tendência é evitar o uso das siglas, assim a tradição de Datã e Abiram simplesmente é pré-sacerdotal e a história de Coré é sacerdotal com acréscimos posteriores.

Em relação à tradição tardia de Coré e os levitas, preferem os autores falar de uma expansão redacional, ou alargamento da tradição sacerdotal ${ }^{53}$. Outros veem o texto não como uma junção mecânica de diferentes estratos, mas positivamente como resultado de uma composição sacerdotal ${ }^{54}$.

\footnotetext{
${ }^{49}$ Cf. LEHMING, S. Versuch zu Nm 16. Zeitschrift für die alttestamentliche Wissenschaft, n. 74, p. 320.

${ }^{50}$ Cf. AHUIS, F. Autorität im Umbruch, p. 24.

${ }^{51}$ AHUIS, F. Autorität im Umbruch, p. 24; AURELIUS, E. Der Fürbitter Israels, p. 194-202; SCHORN, V. Rubeniten als exemplarische Aufrührer in Num 16f/Deut.11. Beiträge Zeitschrift für die Alttestamentliche Wissenschaft. vol. 294, p. 251.

${ }^{52}$ Cf. SCHMIDT, L. Studien zur Priesterschrift, Beträge Zeitschrift für die alttestamentliche Wissenschaft n. 214 (1993), p. 113-179. O autor não menciona as datas das referidas camadas sacerdotais. ${ }^{53}$ Cf. SCHORN, U. Rubeniten als exemplarische Aufrürer in Num 16f/Deut 11. Beiträge Zeitschrift für die Alttestamentliche Wissenschaft. vol. 294, p. 251; SCHMIDT, L. Studien zur Priesterschrift, Beträge Zeitschrift für die alttestamentliche Wissenschaft, vol. 214, p. 113-179. A propósito, nos últimos anos aumentam os autores que falam de adições redacionais sucessivas ("Fortschreibung") do Pentateuco, até chegar à fixação definitiva do texto canônico (cf. GARCIA LOPES, O Pentateuco, p. 289).

${ }^{54}$ Assim E. BLUM (Komposition des Priesterschrift, p. 229), prefere o termo "composição sacerdotal" e não documento sacerdotal.
} 
Admite-se a fusão de fontes diferentes no mesmo relato, porém seria no mínimo temerário estabelecer uma delimitação precisa do material provindo de uma fonte ou de outra, especialmente em textos corrompidos como $\mathrm{Nm} \mathrm{16,1-35}$. Além do mais, devido à crise que se instalou, "dificilmente temos um modelo confiável para datar os textos do Pentateuco" 56 . Por isso, dada a incerteza da exegese do Pentateuco, alguns comentários relatam com brevidade os resultados das pesquisas de crítica de fonte, alegando que tal procedimento exegético é artificial e, muitas vezes, baseado mais no entendimento do intérprete do que nas evidências textuais ${ }^{57}$. Às vezes, até priva-se o relato de seu desígnio literário ${ }^{58}$. Diante disso, será melhor utilizar com cautela o método histórico-crítico, de modo particular a crítica de fonte.

$\mathrm{Na}$ medida do possível é melhor trabalhar os métodos diacrônicos de forma integrada com os estudos sincrônicos ligados às ciências da linguagem ${ }^{59}$.

\section{4- Considerações sobre a pesquisa diacrônica de Nm 16-17}

a) A pesquisa diacrônica de Nm 16-17 explica sua composição por meio da fusão de uma antiga história de revolta de Datã e Abiram, que reúne tradições de murmuração e revolta da marcha no deserto, com a história de Coré, proveniente de um contexto sacerdotal mais tardio. O material sacerdotal incorporado no texto transformou a afronta à autoridade de Moisés,

\footnotetext{
${ }^{55}$ Opinião de O. ARTUS (cf. Etudes sur le Livre des Nombres. Fribourg, Editions Universitaires, 1997, p. 168).

${ }^{56}$ RENDTORFF, R. Das überlieferungsgeschichtliche Problem des Pentateuch, p. 169, citado in: WENHAM, G. J. Números, p. 27.

${ }^{57}$ ASHLEY, T. R. The Book of Numbers. Michigan, Eerdmans Publishing, 1993, p. 302.

${ }^{58}$ Cf. WENHAM, G. B. Números, p. 23.149.

${ }^{59}$ Cf. GARCIA LOPES, F. O Pentateuco, p. 13. No prólogo do comentário o autor se perguntava até que ponto deveria prescindir dos estudos histórico-crítico tão desprestigiados em alguns setores, ou se conviria apostar exclusivamente pelos estudos literários ou teológicos. F. Garcia Lopes preferiu antes integrar na medida do possível os estudos sincrônicos e diacrônicos na sua abordagem dos cinco primeiros livros da Bíblia. Apesar do fogo cruzado contra a crítica literária clássica, alguns autores recentes vieram em sua defesa. "Quem poderá contar - se pergunta $\mathrm{H}$. J. Kraus - os nomes de todos os exegetas que dependem de Wellhausen nas questões decisivas de seu trabalho científico?" (KRAUS, H. J. Geschichte der historisch-kritischen Erforschung des Alten Testaments, Neukirchen-Vluyn, 1982, p. 258s. 275, citado e comentado in: GARCIA LOPES, F. O Pentateuco, p. 38). E. W. Nicholson defende que a hipótese documentária, ainda que necessite de algumas revisões, é ainda a que melhor explica o desenvolvimento do Pentateuco e que está longe de seu desaparecimento (NICHOLSON, E. W. The Pentateuch in Twentieth Century. The Legacy of Julius Wellhausen, Oxford, 1998, citado e comentado in: GARCIA LOPES, F. O Pentateuco, p. 39, nota 24).
} 
por parte dos rubenitas, em um protesto de um grupo de levitas contra o direito exclusivo da família de Aarão ao sacerdócio. Trata-se de uma história que não é plenamente uniforme, uma vez que reúne grupos diferentes, com interesses diferentes em conflito contra Moisés e Aarão. A tradição de Datã e Abiram (Nm 16,12-15.25.27b-34) tem origem em uma fonte mais antiga, com influência deuteronomista, enquanto a edição levita forma uma camada relativamente recente ${ }^{60}$.

b) Se, de um lado, a existência de diferentes estratos literários em Nm 16 -17, em parte, explica certos problemas de unidade, por outro, tal divisão em diferentes documentos, por atraente que seja, baseia-se muitas vezes em uma arbitrária fragmentação dos versículos, sem considerar a função de cada uma das partes em vista do sentido do texto final. Além do mais, tal divisão em diferentes documentos para explicar os problemas de composição é incerta devido ao estado fragmentário das tradições. Assim sendo, não será possível reconstruir a história de Datã e Abiram independente da história de Coré sem que se façam mudanças significativas no texto ${ }^{61}$. É mais apropriado aplicar os métodos de análise sincrônica do texto final junto com o método da crítica literária tradicional em vista do sentido do texto final.

c) Será difícil também determinar com precisão as diferentes fases de composição. Mais do que junção de diferentes tradições, o texto pode ser fruto do desenvolvimento de uma história primitiva, que foi meditada e desenvolvida por novos enfoques em contextos diferentes ${ }^{62}$. Sem ignorar a contribuição dos métodos diacrônicos na composição e possíveis camadas do texto, também reconhecendo seus limites a pesquisa precisa avançar na abordagem dos elementos narrativos e estilísticos de cada unidade de Nm 16-17, em vista de realçar os elementos de unidade na construção do enredo e depois interpretá-lo ${ }^{63}$. Se existem glosas ou interpolações, elas

\footnotetext{
${ }^{60}$ Esse é o consenso desde A. Kuenen e J. Wellhausen (cf. SEEBASS, H. Numeri 10,11-22,1. Vluyn, Neukirchener Verlag, 2003, p. 175). Com efeito o texto final de Nm 16-17 é claramente caracterizado por um gênero literário e vocabulário próprio sacerdotal (uma composição sacerdotal como prefere E. Blum) e não apresenta indícios suficientes para a hipótese em favor de uma redação final pós-sacerdotal como sugerem H. C. Schmidt e U. Schorn.

${ }^{61}$ Cf. NOTH, M. Numbers, p. 121.

${ }^{62}$ Cf. DE VAULX, J. Les Nombres. Paris. J. Gabalda et Cie Éditeurs, 1972, p. 190-191.

${ }^{63}$ Para realçar a necessidade de outras abordagens do texto, convém citar o comentário de $\mathrm{F}$. Crüsemann em relação a Nm 16-17. "É difícil encontrar coisas intrinsecamente excludentes nesse
} 
foram bem colocadas e revelam o esforço do autor em apresentar um enredo bem construído dramaticamente ${ }^{64}$.

d) Considerando que a Tradição Sacerdotal tenha dado forma final ao texto no período pós exílico, no final da época persa; é nesse contexto que podemos situar sua redação final de $\mathrm{Nm}$ 16-17. Dada a relativa segurança na datação da Tradição Sacerdotal no final do exílio e no pós exílio, é bem provável que nessa época de crise de identidade houvesse a necessidade de um fundamentalismo no sacerdócio, no templo, e no culto visando a sobrevivência da raça judaica. Foi então que as instituições sacerdotais foram reconduzidas à época da marcha do povo no deserto sob a liderança de Moisés e Aarão para dar sustentação teológica aos sacerdotes com a proteção do Senhor. Assim, explica E. Zenger "os redatores sacerdotais trajaram Aarão com o manto do sumo sacerdote pós-exílico, a tenda do encontro transformou-se no templo de Jerusalém, bem como a ideia de uma democracia de base, do serviço sacerdotal de toda a comunidade de Israel, expressa na queixa dos revoltosos em $\mathrm{Nm}$ 16,3, foi suplantada pela separação entre clero e laicato"65. Tudo convergia para uma ordem político-religiosa sob a autoridade do sumo sacerdote no poder.

\section{Referências Bibliográficas}

AHUIS, F. Autorität im Umbruch: Ein formgeschichtlicher Beitrag zur Klärung der literarischen Schichtung und der zeitgeschichtlichen Bezüge von Num 16 und 17. Mit einem Ausblick auf die Diskussion um die Ämter der Kirche. Stuttgart: Calwer Verlag, 1983. 128p. (Calwer Theologische Monographien, 13).

ALBERTZ, R. Historia de la religión de Israel en tiempos del Antiguo Testamento. Volumen II: Desde el Exílio hasta la época de los Macabeus. Traducción Dionísio Mingues. Valladolid: Editorial Trotta 1999. 453p. Titulo original: Religionsgeschichte Israels in alttestamentlicher Zeit. II: Vom Exil bis zu den Makkabaern, 1

texto, colocadas tão imediatamente e diretamente lado a lado. Este seria o lugar em que a crítica literária se faz mais necessária, mas exatamente nestes textos ela não produziu nenhuma explicação convincente" (CRÜSEMANN, F. A Torá. Petrópolis, Vozes, 2002, p. 491).

${ }^{64}$ Cf. LEVINE, B. A. Numbers 1-20, p. 405.

${ }^{65}$ ZENGER, E. Introdução ao Antigo Testamento. 2 edição, São Paulo, Loyola , 2003, p.131. 
ARTUS, O. Etudes sur le Livre des Nombres: Récit, Histoire et Loi en Nb 13,1-20,13. Fribourg: Editions Universitaires; Göttingen: Vandenhoeck \& Ruprecht, 1997. 443p. (Orbis Biblicus et Orientalis, 157).

ASHLEY, T. R. The Book of Numbers. Michigan: Eerdmans Publishing, Printed in the United States of America, 1993. 665p. (The New International Commentary on the Old Testament).

AURELIUS, E. Der Fürbitter Israels: Eine Studie zum Mosebild im Alten Testament. Stockholm: (s.n), 1988. 250p. (Coniectanea Biblica: Old Testament series, 27).

BARAG, B. Some notes on a silver coin of Yohanan the High Priest. The Biblical Archaeologist, New Haven, n. 48, p. 166-168, 1985.

BLUM, E. Studien Zur Komposition des Pentateuch. Berlin \& New York: Walter de Gruyter, 1990. 432p. (Beihefte zur Zeitschrift für die alttestamentliche Wissenschaft, 89).

BO REICKE, I. História do tempo do Novo Testamento: O mundo bíblico de 500 ac. até 100 d.C. 3. ed. Tradução: João Aníbal \& Edwino Royer. São Paulo: Paulus, 1996. 376p. Título original: Neutestamentliche Zeitgeschichte. Die Biblische Welt von 500 v. Chr. Bis 100 n., 1982.

BUDD, P. J. Numbers. Waco \& Texas: General Editors, Word Books, 1984. 409p. (Word Biblical Commentary, 5).

CAMPBELL, F.; O'BRIEN, M. Sources of the Pentateuch: texts, Introduction, annotations. Minneapolis: Fortress Press, 1993. 140p.

CARR, D. M. Journal of Biblical Literature, Sheffield, n. 117, p. 723, 1998.

COATS, G. W. Rebellion in the Wilderness: The Mourmuring Motiv in the Wilderness Traditions of the Old Testament. Nashvile, Abingdon Press, New York, 1968. 287p.

COUTO, A. Pentateuco. O caminho da vida agraciada. Lisboa: Universidade Católica Editora, 2005.

CRÜSEMANN, F. A Torá: Teologia e história social da lei do Antigo Testamento. 2. ed. Tradução Haroldo Reimer. Petrópolis: Vozes, 2002. 599p. Título original: Die Torá, 1992.

DAVIES, E. W. Numbers. London: William B. Eerdmans Publishing Company, 1980. 378p. (New Century Bible Commentary).

DE PURY A. (Org.). O Pentateuco em questão: As origens e a composição dos cinco primeiros livros da bíblia à luz da pesquisa recente. 2. ed. Tradução Lúcia Mathilde Endlich Orth. Petrópolis: Vozes, 2002. 324p. Título original: Le Pentateuche en question. Les origines des cinq premiers livres de la Bible à lumière des recherches récentes, 1989. 
DE VAULX, J. Les Nombres. Paris: J. Gabalda et Cie Éditeurs, 1972. 431p. (Sources Bibliques).

DRIVER. S. R. Introduction to the Literatura of the Old Testament. New edition revised (1913). New York: Charles Scribner's sons, 1950. 577p. (Internacional Theological Library).

FRITZ,V. Israel in der Wüste: Traditionsgeschichtliche Untersuchung des Wüstenüberlieferung des Jahwisten. Marburg: N. G. Elwert Verlag, 1970. 151p. (Marburger Theologische Studien, 7).

GARCIA LOPES, F. O Pentateuco: Introdução à leitura dos cinco primeiros livros da Bíblia. Tradução Alceu Luiz Orso. São Paulo: Ave Maria, 2004. 325p. Título original: El Pentateuco: introdución a la lectura de los cincos primeros libros de la Biblia, 2003.

GRAY, G. B. A critical and exegetical commentary on Numbers. 3. ed. Edinburgh: T. Clark Limited, 1956. 489p.

HAUDEBERT, P. (Dir.). Le Pentateuque: Débats et recherches. XIV congrés de L'Association Catholique Française pour L'etude de la Bible. Paris: Cerf, 1992. 263p. (Lectio Divina, 151).

LAPERROUSSAZ, S. Le régime théocratique juif a-t-il commencé à l'époque perse, ou seulement à l'époque hellénistique? Semítica, Paris, n. 32, p. 93-96, 1982.

LEHMING, S. Versuch zu Num 16. Zeitschrift für die alttestamentliche Wissenschaft, Berlin \& New York, n. 74, p. 291-321, 1962.

LEVINE A. B. Numbers 1-20: A New Translation with Introduction and Commentary. New York: Doubleday, 1993. 495p. (The Anchor Bible).

LIVER, J. Korah, Dathan and Abiram. Scripta Hierosolymitana, Jerusalem, vol. 8, p.189-217, 1961.

LUX, $R$. Und die Erde tät ihren Mund auf... Zum aktuellen Erzählinteresse Israels am Konflikt zwischen Mose und Datan und Abiram in Num 16. In: VIEWEGER, D.; WASCHKE, E. J. Beiträge zur Theologie und Exegese des Alten Testaments, p.187-216, S.Wagner, p. 187-216, 1995.

MAGONET, J. The Korah Rebellion. Journal Study of the Old Testament, Sheffield, n. 24, p. 3-25, 1982.

MAIER, J. Entre os dois Testamentos: Historia e religião na época do segundo templo. Tradução Frederico Stein. São Paulo: Loyola 2005. 335p. Título original: Zwischen den Testamenten. Geschichte und Religion in der Zeit des sweiten Tempels, 1990. (Bíblica Loyola, 46).

NICHOLSON, F. W. The Pentateuch in Twentieth Century. The Legacy of Julius Wellhausen. Oxford: Blacwel,1998. 180p. 
NICHOLSON, E. W. Journal Study of the Old Testament, Sheffield, n. 79, p. 139, 1998.

NOTH, M. Numbers. Translated by James D. Martin. London: SCM Press, 1968. 258p.

RENDTORFF, R. The Old Testament: an Introduction. Translated by John Bowden. Philadelphia: Fortress Press edition, 1986. 308p. Original text: Das Alte Testament, Eine Einführung, 1983.

RÖMER, Th.; LEMAIRE, A. (ed.). "Le Pentateuque toujours en question: Bilan et perspectives après un quart de siècle de débat". Congress Volume Basel, Leiden 2001. (Vetus Testamentum Suplementum, 92).

RÖMER, T. L'Histoire redactionnelle des premiers livres de la bible. Estúdios Bíblicos, Madrid, n. 62, p.137-154, 2004.

RUDOLF, W. Der Elohist “Von exodus bis Josua”. Berlin: Alfred Töpelmann, 1938. 180p.

SCHMIDT, L. Studien zur Priesterschrift. Beiträge Zeitschrift für die alttestamentliche Wissenschaft, Berlin \& New York, vol. 214, p.113-179, 1993.

SCHORN, U. Rubeniten als exemplarische Ausfrührer in Num. 16f /Deut.11. Beiträge Zeitschrift für die alttestamentliche Wissenschaft. Berlin \& New York, vol. 294, p. 252-268, 2000.

SEEBASS, H. Numeri 10,11-22,1. Vluyn: Neukirchener Verlag, 2003. 320p. (Biblischer Kommentar Altes Testament, IV/1).

SKA, J. L. Introduzione Alla Lettura Del Pentateuco. Roma: Edizioni Dehoniane, 2000. 314p.

SKA, J. L. Res Bibliographicae: Le Pentateuque: état de la recherche à partir de quelques récentes "Introductions". Biblica, Roma, vol. 77, p.345-365, 1996.

SKA, J. L. Res Bibliographicae: Le Pentateuque à l'heure de ses usagers. Biblica, Roma, vol. 87, fasc.1, p. 98-110, 2006.

WENHAM, G. J. Números: Introdução e Comentário. Tradução Adiel Almeida de Oliveira. São Paulo: Sociedade Religiosa Edições Vida Nova \& Associação Religiosa Editora Mundo Cristão, 1985. 250p. Título original: Numbers: An Introduction and Commentary, 1981.

WellHaUSEN, J. Die Composition des Hexateuchs und der Historischen Bücher des Alten Testaments. 4 ed. Berlin: Georg Reimer, 1963. 490p.

WELlHAUSEN, J. Prolegomena zur Geschichte Israels. 6 ed. Berlim \& Leipzig: Walter de Gruyter, 1927. 424p. 
ZENGER, E. et. al. Einleitung in das Alte Testament. 5. ed. Stuttgart; Berlin; Köln: Kohlhammer Studienbücher Theologie, 2004. 598p.

ZENGER, E. Et. Al. Introdução ao Antigo Testamento. 2.ed. Tradução de Werner Fuchs. São Paulo, Loyola, 2003. 557p. Título original: Einleitung in das Alte Testament, 1995.

ZWICKEL, W. Räucherkult und Räuchergerät. Fribourg: Editions Universitaires; Göttingen: Vandenhoeck \& Ruprecht, 1990. 350p. (Orbis Biblicus et Orientalis, 97)

Vicente Artuso

Doutor em Teologia Bíblica pela PUC-Rio Mestre em Ciências Bíblicas pelo PIB-Roma, Itália Professor Adjunto do Mestrado em Teologia da PUCPR de Curitiba-PR e na Graduação em Londrina-PR

Artigo Recebido em 27/07/2011 Artigo Aprovado em 21/11/2011 